\section{Contamination level and exposure assessment to Aflatoxin M1 in Jordanian infant milk formulas}

\author{
Saddam S. Awaisheh, ${ }^{1}$ \\ Razan J. Rahahleh, ${ }^{1}$ Rania M. Algroom, ${ }^{2}$ \\ Ala'a A. Al-Bakheit, ${ }^{1}$ \\ Ja'far M. Al-Khaza'leh, ${ }^{1}$ \\ Basim A. Al-Dababseh ${ }^{1}$ \\ ${ }^{1}$ Department of Nutrition and Food \\ Processing; ${ }^{2}$ Department of Food \\ Science, Al-Balqa Applied University, \\ Jordan
}

\begin{abstract}
Aflatoxin M1 (AFM1) is a principal hydroxylated-aflatoxin B1 (AFB1) metabolite, and has been classified as possible human carcinogen (group 2B). The aim of this study was to survey the contamination level, estimated daily intake (EDI) and tolerable daily intake \% (TDI\%) of AFM1 in Jordanian infant milk formulas. A total of 120 samples, 48 starter and 72 follow-on formula samples were collected and analyzed using ELISA technique. Of the 120 surveyed samples, $58(48.33 \%)$ were AFM1-positive and exceeded the EU maximum limit for AFM1 in IMF (25 ng/ $\mathrm{kg}$ ). The average AFM1 concentration was 69.93 and $84.78 \mathrm{ng} \mathrm{AFM} 1 / \mathrm{kg}$, with range of $<5-89.25$ and $<5-213.84$ ng AFM1/kg in starter and follow-on formula, respectively. It is also noteworthy the high EDI of AFM1 by infants (1.557 and $1.551 \mathrm{ng}$ AFM $1 / \mathrm{kg}$ b.w./day), and the high TDI\% values (786.9 and $775.9 \%$ ). In addition, current study indicated high-extrapolated AFB1 content in the feed; accordingly, raised the need to implement good agricultural and hygienic practices as preventive and controlling measures to decrease AFM1 in milk and IMF through controlling AFB1 in feed at the farm level. Finally, it is obvious that the contamination of IMF by AFM1 is an international problem, and the protection of infants and young children against AFM1 in Jordan requires a fundamental setup of clear legal limits of AFM1 in Jordanian standards and strict monitoring and continual analysis of IMF traded and consumed in Jordan.
\end{abstract}

\section{Introduction}

Mycotoxins are highly toxic secondary metabolites produced by mold genera, such as Aspergillus, Fusarium and Penicillium
(Kumar et al., 2008; Sweeney \& Dobson, 1998). Aflatoxins (AFs) are the most carcinogenic mycotoxins metabolites produced mainly by strains of Aspergillus (A.) flavus and A. parasiticus. Majority of the food isolated AFs are aflatoxin B1, B2, G1, G2, M1, and M2 (AFB1, AFB2, AFG1, AFG2, AFM1, AFM2) (Alshannaq \& Yu, 2017; Kumar et al., 2008). AFM1 is a principal hydroxylated-AFB1 metabolite that is biotransformed by hepatic microsomal cytochrome upon ingestion of AFB1 in feed, and usually excreted in milk (Alshannaq \& Yu, 2017).

AFs accumulate in body and cause adverse health effects, including carcinogenic, mutagenic, teratogenic, nephrotoxic, hepatotoxic and immunosuppressive effects, as well as developmental and birth defects (IARC, 2012). AFB1 has been classified as the strongest naturally occurring human carcinogen (group 1), while AFM1 has been classified as possible human carcinogen (group 2B) (IARC, 2012). The main AFM1 target organ in human body is the liver so it is primarily a hepatic disease. Milk is the main risk factor of human exposure to AFM1. Milk is considered as the perfect food for adults and infants, providing the major vital and functional ingredients for human life (Awaisheh et al., 2012, Awaisheh et al., 2013, Rababah et al., 2015). Infants are the foremost milk consumers and the most vulnerable group in population, which make them more susceptible to the adverse effects of AFM1, particularly hepatocellular carcinoma (WHO, 2014). Therefore, the incidence of AFM1 in milk and milk products is a serious health concern. The level of AFM1 in milk depends on the level of AFB1 in feeds. The contamination of milk and milk products by AFM1 is an inevitable process as at least $25 \%$ of the world's crops are contaminated with mycotoxins including AFB1, and large amount of these crops are used for dairy cows feeding (FAO, 2003). Moreover, AFM1 is heat stable and can resist various thermal treatments, and is almost entirely retained in pasteurized, powdered and infant milk formula (IMF) (Galvano et al., 2001). Therefore, the incidence of AFM1 in milk and milk products cannot be prevented but can be controlled by restricting the level of AFB1 in feeds.

Internationally, the needs emerged and insisted on the importance of surveying and controlling the levels of AFM1 in various dairy products, with more attention to IMF. Therefore, the EU and Codex Alimentarius legal maximum tolerance limits (MTL) for AFM1 in IMF was $25 \mathrm{ng} / \mathrm{kg}$ (EC Regulation, 2006), with a tolerable daily intake (TDI) of $0.2 \mathrm{ng} / \mathrm{kg}$ b.w./day (Kuiper-
Correspondence: Saddam S. Awaisheh, Department of Nutrition and Food Processing, Al-Balqa Applied University, 19117 Salt, Jordan.

Tel.: +96.2795404862

E-mail: saddam_awaisheh@yahoo.com

Key words: Aflatoxins M1, Estimated Daily Intake, Infants milk formula, contamination level, exposure assessment, Jordan.

Contributions: SA, RR, research design and conducting, data collecting and analyzing; RE, AA, manuscript writing; JA, manuscript writing and reviewing; BA references writing and reviewing.

Conflict of interest: the authors declare no potential conflict of interest.

Funding: this work was financially supported by Abdul Hameed Shoman Fund for Supporting Scientific Research.

Received for publication: 3 May 2019.

Revision received: 3 July 2019.

Accepted for publication: 8 July 2019.

This work is licensed under a Creative Commons Attribution-NonCommercial 4.0 International License (CC BY-NC 4.0).

CCopyright: the Author(s), 2019

Licensee PAGEPress, Italy

Italian Journal of Food Safety 2019; 8:8263 doi:10.4081/ijfs.2019.8263

Goodman, 1989). However, recent studies reported the increasing incidence AFM1 in IMFs, with many samples exceeding the international MTL (El-Tras et al., 2011; Kabak, 2012; Ghanem, 2009; Sadeghi et al. 2009). These reports drew the attention to the high health and life-threatening risks the infants may expose to upon consuming such contaminated products.

Despite the high risks of mycotoxins on human health, particularly infant's health, surprisingly, official Jordanian standards of IMFs lack clear legal limits of AFM1 in these formulas, which implies that these formulas are not officially and routinely tested for AFM1. Upon extensive search, only one small-scale study by Omar (2016) was found in Jordan, where results of 20 samples showed that the level of AFM1 in $85 \%$ of IMF samples was higher than MTL, with average of $120.26 \mathrm{ng} / \mathrm{kg}$ and range from 16.55 to $288.68 \mathrm{ng} / \mathrm{kg}$. Despite the important evidence these results might prevail about the health risks the infants in Jordan might be exposed to due to AFM1 contamination, the limited number of surveyed samples in this study is a serious limiting factor and could not give an actual pic- 
ture about the contamination level of AFM1 in IMF in Jordan. In addition, this study did not assess the exposure risk assessment of Jordanian infants to AFM1 in IMF. For these reasons, the aim of this work was to assess the risk of exposure of Jordanian infants to AFM1 through determination the levels of AFM1 in expanded samples size of the leading brands of IMF marketed in Jordan using ELISA.

\section{Materials and Methods}

\section{Samples collection}

Total of 120 powdered IMF samples representing the most traded IMF brands in Jordan $(\mathrm{n}=15 ; 3$ different batch numbers from each brand), were randomly collected from different markets and pharmacies in Jordan during March and September 2016. Collected samples were from local and imported sources, and classified as starter formula (given to infants during the first 6 months of age, 48 samples) and follow-on formula (given to infants from the 6 th month on and for young children, 72 samples) (Table 1). Samples were stored in plastic bags at $-20^{\circ} \mathrm{C}$ until the analysis.

\section{Samples preparation}

A portion of $10 \mathrm{~g}$ from IMF samples was dissolved in $100 \mathrm{ml}$ double distilled water, warmed up to $50^{\circ} \mathrm{C}$ and stirred on a stirrer hot plate, and centrifuged at $3500 \mathrm{~g}$ for 10 $\min$ at $10^{\circ} \mathrm{C}$. The upper fat layer was skimmed, and milk serum was directly assayed for AFM1 using a specific ELISA kit.

\section{Analysis of AFM1 by competitive enzyme linked immunosorbent assay (ELISA)}

Determination of AFM1 was carried out using Ridascreen Aflatoxin M1 competitive ELISA kit (Art No. R1121) from R-biopharm (Derm-Stadt, Germany), with detection limit of 5 ppt. Before use, the kit was kept at room temperature $\left(20-25^{\circ} \mathrm{C}\right)$ for $1 \mathrm{~h}$. For the preparation of standard curve, AFM1 standard solutions of $0,5,10,20,40$, and 80 ppt were provided with the kit. Samples analysis was carried out according to the manufacturer's instructions. Briefly: AFM1-microtiter plate was pipetted with
$100 \mu \mathrm{L}$ of antibody solution into each well. The plate was gently mixed by manual shaking and incubated for $15 \mathrm{~min}$ at $25^{\circ} \mathrm{C}$, wells were then washed twice by $250 \mu \mathrm{L}$ of washing buffer and tapped upside down vigorously against absorbent paper. A 100 $\mu \mathrm{L}$ of the standard solutions or prepared samples was added in duplicate to separate wells, gently mixed and incubated in dark for $30 \mathrm{~min}$ at $25^{\circ} \mathrm{C}$. Wells were washed out again as above described. A $100 \mu \mathrm{L}$ of conjugate solution was added into wells, gently mixed and incubated in dark for $15 \mathrm{~min}$ at $25^{\circ} \mathrm{C}$, then washed out twice again. A 100 $\mu \mathrm{L}$ of substrate/chromogen solution was then added to each well, mixed gently and incubated in dark for $15 \mathrm{~min}$ at $25^{\circ} \mathrm{C}$, followed by adding $100 \mu \mathrm{L}$ of the stop solution $\left(\mathrm{H}_{2} \mathrm{SO}_{4}\right)$ to each well. The absorbance was measured at $450 \mathrm{~nm}$ in Bioteck-XLD800 Multi Scan Plate Reader (Bioteck, VA, USA), and the absorption intensity was inversely proportional to samples AFM1 contents. AFM1 sheet supplied with the kit was used to generate a standard curve and to calculate the concentration of AFM1 in the samples.

\section{Infants estimated daily intake (EDI) of AFM1}

The infants EDI of AFM1 was calculated from the daily intake of starter and follow-on formula, the average AFM1 level in IFM samples, and mean body weight (b.w.) for infants (Bogalho et al., 2018). The two daily IMF consumption estimates were considered: $150 \mathrm{~mL} / \mathrm{kg} \mathrm{b}$. wt. (for babies of 6 months age with $6.5 \mathrm{~kg}$ b.w.) and $1 \mathrm{~L}$ (for infants of 12 months age with $8.2 \mathrm{~kg}$ b.w.). According to the IMF manufacturers, $4.5 \mathrm{~g}$ IMF was required to prepare $30 \mathrm{~mL}$ of ready milk formula. The EDI was calculated according to Bogalho et al. (2018):

$$
\begin{aligned}
& \text { EDI }(\mathrm{ng} / \mathrm{kg} \text { b.w./day })=[\text { AFM1 }] \times \\
& {[\text { milk consumption }] /[\text { b.w. }]}
\end{aligned}
$$

The percentage of TDI from consumption of IMF was calculated as follows:

$$
\text { TDI } \%=\text { EDI } / \text { TDI } \times 100
$$

where TDI was derived from formula of Kuiper-Goodman (1990).
Calculation of extrapolated values of aflatoxin $B 1$ concentration in feeds

A linear relationship was proposed between the concentration of AFB 1 in feeds consumed by animals like cows and AFM1 in milk and only $1.6 \%$ of ingested AFB 1 is bio transformed to AFM1 by the dairy cattle (Pettersson, 1998). According to Price et al. (1985) the expected concentrations of AFB1 in animal feeds can be back calculated from the concentrations of AFM1 of IMF samples. Therefore, the values of AFB1 contamination in dairy animal feeds were back calculated by the formula given below:

$$
\begin{gathered}
\text { AFB } 1(\mu \mathrm{g} / \mathrm{kg})=[\text { AFM1 }(\mathrm{ng} / \mathrm{kg}) \times \\
100] / 1.6 / 1000 .
\end{gathered}
$$

\section{Results and Discussion}

\section{Contamination level of AFM1 in infant starter and follow-on milk formula}

The current study is the first ever largescale study surveying the AFM1 level in IMF in Jordan. Contamination level of AFM1 in 120 IMF samples (48 starters and 72 follow-on) was screened. Results revealed that 58 of 120 samples $(48.33 \%)$ were contaminated with AFM1 above the international MTL (25 ng/kg). The average of AFM1 was $74.26 \mathrm{ng} / \mathrm{kg}$ and ranged from $<5-213.84 \mathrm{ng} / \mathrm{kg}$. In detail, 24 samples $(50 \%)$ and 34 samples $(47.23 \%)$ of the starter and follow-on formulas were contaminated with AFM1 above MTL, with average of 69.93 and $84.78 \mathrm{ng} / \mathrm{kg}$, and range of $<5-89.25$ and $<5-213.84 \mathrm{ng} / \mathrm{kg}$, respectively (Table 1 ).

In agreement but higher than our findings, the only study found in Jordan (Omar, 2016) reported $85 \%$ incidence rate and $120.26 \mathrm{ng} / \mathrm{kg}$ average contamination level of AFM1 in IMF. This higher incidence rate and contamination level could be due to the small samples size surveyed, 20 samples. However, several international studies revealed same high incidence and contamination level of AFM1 in IMF. For example,

\begin{tabular}{|c|c|c|c|c|c|c|}
\hline Milk type & No. samples & Negative (\%) & Non-violative positive & Violative positive & Average ng/kg & Min - Max ng/kg \\
\hline Starter (0-6 months) & 48 & $24(50)$ & 0 & $24(50)$ & $69.93 \pm 5.66$ & $<5-89.25$ \\
\hline Follow up (6-36 months) & 72 & $38(52.77)$ & 0 & $34(47.22)$ & $84.78 \pm 9.34$ & $<5-213.84$ \\
\hline Total & 120 & $62(51.67)$ & 0 & $58(48.33)$ & $74.26 \pm 7.54$ & $<5-213.84$ \\
\hline
\end{tabular}
in Syria the incidence rate of AFM1 in milk used for infants was $80 \%$ of tested samples with range of $20-765 \mathrm{ng} / \mathrm{l}$ (Ghanem, 2009).

Table 1. Numbers (\%) of AFM1 negative, non-violative-positive and violative-positive in milk samples.

Negative samples: samples with no detected aflatoxin; Non-violative-positive sample: samples with detected aflatoxin below $25 \mathrm{ng} / \mathrm{kg}$; and Violative-positive: samples with aflatoxin exceeding $25 \mathrm{ng} / \mathrm{kg}$. 
Another study in Italy reported that AFM1 was found in 49 (53\%) dry infant milk samples, with range of $<1-79.6 \mathrm{ng} / \mathrm{kg}$ with mean level of $32.2 \mathrm{ng} / \mathrm{kg}$ (Galvano et al., 2001). In a Korean study, the incidence of AFM1 in IMF was $85 \%$ of the samples, with average of $46 \mathrm{ng} / \mathrm{kg}$ (Kim et al., 2000). Moreover, Baydar et al. (2007) found that $36.5 \%$ of 63 IMF samples contained AFM1 between $0.06-0.32 \mathrm{ppb}$ in Turkey. However, it is quite obvious and crucial that the contamination of IMF with AFM1 is an international problem, and the protection of infants and young children from AFM1 requires fundamental national and international cooperation and far-reaching revisions of national and international regulations and approaches of surveillance, toxicity and risk assessment of AFM1 (Juan et al., 2014).

\section{Exposure assessment of Jordanian infants to AFM1 from IMF}

Up to our best knowledge, this is the first ever study to assess the EDI of AFM1 by Jordanian infants. Unexpectedly, the current results revealed a high EDI and TDI \% values of AFM1 for both age groups ( 6 and 12 months) (Table 2). EDI results were 1.573 and $1.551 \mathrm{ng} / \mathrm{kg}$ b.w./day for 6- and 12-months infants age, respectively. The current EDI values exceeded the international TDI values $(0.2 \mathrm{ng} / \mathrm{kg}$ b.w./day) by 7.869 and 7.759 times for both age groups, respectively. In comparison to international studies, our results were lower and higher than the results of several studies. Lower than our results, Henry et al. (2001) showed that the maximum EDI was 0.48 and 0.55 ng AFM1 $/ \mathrm{kg} . b w /$ day for infants in Catalonia and France, respectively. Ishikawa et al. (2016) reported lower EDI values $(0.078-0.306 \mathrm{ng}$ AFM $1 / \mathrm{kg}$ b.w./day) than ours in IMF in Brazil. A study by Oliveira et al. (1997) showed higher EDI than our results, where EDI value was $3.7 \mathrm{ng}$ AFM1/kg b.w./day for 4 months infant (6 kg weight), representing $22 \mathrm{ng}$ daily intake of AFM1. However, several other studies reported a variable EDI results in different countries (Spain, Argentina, and Thailand), with values of $0.16-3.70 \mathrm{ng}$ AFM1/kg b.w./day (Cano-Sancho et al., 2010, Alonso et al., 2010, Ruangwises et al., 2011). For Jordan, there are no data available about the EDI values and exposure risks to AFM1 by Jordanian infants. The important issue emerges here is the high-risk possibility of infant's exposure to AFM1 from IMF in Jordan and the world.

\section{Extrapolated concentration of afla- toxin $B 1$ in animal feeds}

AFM1 is heat stable $\left(\leq 120^{\circ} \mathrm{C}\right)$ and cannot be removed or eliminated by chemical or physical treatments, thus monitoring of AFB1 levels in animal feeds is the only effective measure to control contamination of AFM1 in milk and thus IMF (JECFA, 2001). The maximum allowed contents of AFB1 in complete feeds has been established at $5 \mu \mathrm{g} \mathrm{AFB} 1 / \mathrm{kg}$ feed for dairy animals such as cattle, sheep and goats (EC, 2003). Our results in Table 3 showed that the range of feed extrapolated AFB1 content of milk of starter formula was $<0.313-$ $5.578 \mu \mathrm{g}$ AFB $1 / \mathrm{kg}$, whereas that of followon formula was $<0.313-13.365 \mu \mathrm{g}$ AFB $1 / \mathrm{kg}$. The average range of feed extrapolated AFB1 content of both formula types was $<0.313-13.365 \mu \mathrm{g}$ AFB1/kg. Current results indicated that AFB1 extrapolated content in feed is marginal, and this extrapolated content could pose a serious health problem over the long time of consuming milk by infants. In comparison to our

Table 2. Estimated Daily Intake (EDI) and tolerable daily intake\% (TDI\%) of AFM1 by infants in Jordan.

\begin{tabular}{lcccc} 
Age & $\begin{array}{c}\text { Milk intake } \\
\text { (weight of powder milk) }\end{array}$ & $\begin{array}{c}\text { Average } \\
\text { b.w. (kg) }\end{array}$ & $\begin{array}{c}\text { EDI } \\
\text { (ng/kg b.w/Day) }\end{array}$ & \%'TDI \\
\hline 6 months & $975 \mathrm{~mL}(146.23 \mathrm{~g})$ & 6.5 & $1.573 \pm 0.154$ & 786.9 \\
12 months & $1000 \mathrm{~mL}(150 \mathrm{~g})$ & 8.2 & $1.551 \pm 0.171$ & 775.9 \\
\hline
\end{tabular}

Table 3. Extrapolated values of Aflatoxins B1 concentration in animal feeds in naturally contaminated IMF.

\begin{tabular}{lcc} 
Millk type & AFM1 (ng/kg) & AFB1 ( $1 \mathrm{gg} / \mathrm{kg})$ \\
Starter (0-6 months) & $<5-89.25$ & $<0.313-5.578$ \\
Follow up (6-36 months) & $<5-213.84$ & $<0.313-13.365$ \\
\hline Total & $<5-213.84$ & $<0.313-13.365$ \\
\hline
\end{tabular}

[Italian Journal of Food Safety 2019; 8:8263]

results, Omar (2016) reported high-extrapolated AFB1 values for fresh and pasteurized cow's milk, the results ranged from 0.6 to 8.1 and 0.9 to $13.5 \mu \mathrm{g} \mathrm{AFB} 1 / \mathrm{kg}$, respectively. Current findings advise that the best measure to control AFM1 in IMF should start at the farm level to ensure the safety of milk used in IMF processing through controlling the contamination level of AFB1 in feeds by applying the good agricultural and good hygienic practices at the farm level.

\section{Conclusions}

The present results reported the first study of AFM1 level and EDI in IMF in Jordan. Of the 120 surveyed samples, 58 $(48.33 \%)$ were AFM1-positive and exceeded the EU maximum limit. The maximum AFM1 values detected was 89.25 and $213.84 \mathrm{ng}$ AFM1/kg of starter and followon formula, respectively. It is also noteworthy the high EDI of AFM1 by infants (1.557 and $1.551 \mathrm{ng}$ AFM1/kg b.w./day), and the high TDI\% values (786.9 and $775.9 \%$ ). The findings of the current study indicated highextrapolated AFB1 content in feed and accordingly raised the need to reinforce application of good agricultural and good hygienic practices as preventive and control measures to decrease AFM1 in milk and IMF through controlling AFB1 in feed at the farm level. Moreover, it is very important to setup clear legal limits of AFM1 in IMF in Jordanian standards.

\section{References}

Alonso V, Monge M, Larriestra A, Dalcero A, Cavaglieri L, Chiacchiera S, 2010. Naturally occurring aflatoxin M1 in raw milk from farm cooling tanks in Argentina. Food Addit Contam Part A Chem Anal Control Expo Risk Assess 27:373-9.

Alshannaq A, Yu J-H, 2016. Review. Occurrence, Toxicity, and Analysis of Major Mycotoxins in Food. Int J Envir Res Pub Health 14:632-51.

Awaisheh SS, Khalifeh MS, Al-Ruwaili MA, Khalil OM, Al-Ameri OH, AlGroom R, 2013. Effect of supplementation of probiotics and phytosterols alone or in combination on serum and hepatic lipid profiles and thyroid hormones of hypercholesterolemic rats. J Dairy Sci 96:9-15.

Awaisheh S, Al-Dmoor H, Omar S, Hawari A, Al-Rwaily M, 2012. Impact of selected nutraceuticals on viability of probiotic strains in milk during refriger- 
ated storage at $4^{\circ} \mathrm{C}$ for 15 days. Inter $\mathrm{J}$ Dairy Tech 65:268-73.

Baydar T, Erkekoglu P, Sipahi H, Şahin G, 2007. Aflatoxin B1, M1 and Ochratoxin A levels in infant formulae and baby foods marketed in Ankara, Turkey. J Food Drug Anal 15:89-92.

Bogalho F, Duarte S, Cardoso M, Almeida A, Cabeças R, Lino C, Pena A, 2018. Exposure assessment of Portuguese infants to Aflatoxin M1 in breast milk and maternal social-demographical and food consumption determinants. Food Control 90:140-5.

Cano-Sancho G, Marin S, Ramos AJ, PerisVicente J, Sanchis V, 2010. Occurrence of aflatoxinM1 and exposure assessment in Catalonia (Spain). Rev Iberoam Micol 27:130-5.

European Commission. Commission Regulation of 19 December setting maximum levels for certain contaminants in foodstuffs, 1881/2006/EU. In: Official Journal 2006; L 364, e24

European Commission. Commission Directive 2003/100/EC of 31 October of 2003 Amending Annex I to Directive 2002/32/EC of the European Parliament and of the Council on Undesirable Substances in Animal Feed. EUR-Lex. Available from: https://eurlex.europa.eu/LexUriServ/LexUriServ. do?uri=OJ\%3AL $\% 3 \mathrm{~A} 2003 \% 3 \mathrm{~A} 285 \% 3$ A $0033 \% 3$ A0037\%3AEN $\% 3$ APDF (accessed on 23 February 2019).

El-Tras WF, El-Kady NN, Tayel AF, 2011. Infant's exposure to aflatoxin M1 as a novel foodborne zoonosis. Food Chem Toxicol 49:2816-9.

Food and Agriculture Organization of the United Nations (FAO), 2003. Manual on the application of the HACCP system in mycotoxin prevention and control. FAO Food Nutr Paper 73:1-124.

Galvano F, Galofaro V, Ritieni A, Bognanno M, De Angelis A, Galvano G, 2010. Survey of the occurrence of aflatoxin M1 in dairy products marketed in Italy: second year of observation. Food Addit Conta 18:644-6.
Ghanem I, Orfi M, 2009. Aflatoxin M1 in raw, pasteurized and powdered milk available in the Syrian market. Food Control 20:603-5.

Henry SH, Whitaker T, Rabbani I, Bowers J, Park D, Price W, Bosch FX, Pennington J, Verger P, Yoshizawa T, van Egmond $\mathrm{H}$, Jonker MA, Coker R, 2001. Aflatoxin M1. Joint FAO/WHO Expert Committee on Food Additives (JECFA). pp: 47.

IARC. WHO Working Group on the Evaluation of Carcinogenic Risks to Humans. Chemical agents and related occupations. IARC monographs on the evaluation of carcinogenic risks to humans 2012; 100: 9.

Ishikawa AT, Takabayashi-Yamashita RC, Ono YSE, Bagatin AK, Rigobello FF, Kawamura O, Hirooka EY, Itano E, 2016. Exposure Assessment of Infants to Aflatoxin M1 through Consumption of Breast Milk and Infant Powdered Milk in Brazil. Toxins 8:246-57

Joint FAO/WHO Expert Committee on Food Additives (JECFA), 2001. Safety evaluation of certain mycotoxins in food. WHO Food Addit Ser 47:103279.

Juan C, Raiola A, Mañes J, Ritieni A, 2014. Presence of mycotoxin in commercial infant formulas and baby foods from Italian market. Food Control 39:227-36.

Kabak B, 2012. Aflatoxin M1 and ochratoxin $\mathrm{A}$ in baby formulae in Turkey: Occurrence and safety evaluation. Food Control 1:182-7.

Kim EK, Shon DH, Ryu D, Park JW, Hwang HJ, Kim YB, 2000. Occurrence of aflatoxin M1 in Korean dairy products determined by ELISA and HPLC. Food Additi Contam 17:59-64.

Kuiper-Goodman T, 1990. Uncertainties in the risk assessment of three mycotoxins: aflatoxin, ochratoxin, and zearalenone. Canad J Physiol Pharmacol 68:1017-24.

Kumar V, Basu MS, Rajendran TP, 2008. Mycotoxin research and mycoflora in some commercially important agricul- tural commodities. Crop Protection 27:891-905.

Oliveira CA, Germano PM, Bird C, Pinto CA, 1997. Immunochemical assessment of aflatoxin M1 in milk powder consumed by infants in São Paulo, Brazil. Food Addit Contam 14:7-10.

Omar SS, 2016. Aflatoxin M1 levels in raw milk, pasteurised milk and infant formula. Ital J Food Saf 5:5788-90.

Pettersson H, 1988. Carryover of aflatoxin from feeding stuff to milk. Report of Department of Animal Nutritionand Management. Swedish University of Agricultural Sciences, Upsala, Sweden.

Price R, Paulson H, Lough G, Ginng C, Kurtz G, 1985. Aflatoxin conversion by dairy cattle consuming naturally contaminated whole cottonseed. J Food Protect 48:11-5.

Rababah TM, Al-Tamimi HJ, Awaisheh SS, Brewer S, 2015. The hypocholesterolemic and hormones modulation effects of isoflavones alone or co-fermented with probiotic bacteria in hypercholesterolemic rats model. Inter J Food Sci Nutr 66:546-52.

Ruangwises N, Saipan P, Ruangwises S, 2011. Estimated daily intake of AFM1 in Thailand. In AflatoxinsBiochemistry and Molecular Biology; Guevara-Gonzalez, R., Ed.; InTech: Rijeka, Croatia, 439-46.

Sadeghi N, Oveisi MR, Jannat B, Hajimahmoodi M, Bonyani H, Jannat F, 2009. Incidence of aflatoxin M1 in human breast milk in Tehran, Iran. Food Control 20:75-8.

Sweeney MJ, Dobson AD, 1998. Mycotoxin production by Aspergillus, Fusarium and Penicillium species. Inter J Food Microbiol 43:141-58.

World Health Organization (WHO). Infant and Young Child Feeding 2014; No. 342. Available online: http://www.who.int/mediacentre/factsheets/fs342/en/ (accessed: 2 Nov 2018). 